\title{
USING A TEAM PROJECT IN TEACHING COMPUTER NETWORKING AND DATA COMMUNICATION
}

\author{
Ping Wang, Robert Morris University, wangp@rmu.edu \\ Raed Sbeit, University of Cumberlands, raed.sbeit@ucumberlands.edu
}

\begin{abstract}
Computer networking and data communication is one of the most challenging areas for teaching and learning due to the highly technical and complex nature of the subject. Team projects may foster collaborative learning and teamwork skills. This study proposes a comprehensive and constructive team project design model for teaching computer network and data communication. The team project instructional design emphasizes the team assignment planning, teaching presence, learning community, accountability, and assessment presence with reflective self and peer evaluations for successful teamwork. The study shares the pedagogical design and instructional experience and findings from a team project for network troubleshooting used in an undergraduate computer network and data communication course at a U.S. university. The study also presents findings and discussions on the assessment results, peer reviews and observations on student performance, and student perceptions related to the team project.
\end{abstract}

Keywords: Networking, data communication, teamwork, team project, learning community, troubleshooting, problem solving, assessment, peer reviews

\section{INTRODUCTION}

Computer networking and data communication is an essential component of the college curriculum for the fastgrowing computer and information technology field. The technical complexities of computer networks and data transmission processes and protocols present immense challenges for teaching and learning in computer network education. Students often need to have intensive studying and practical experience with hands-on activities in order to understand the large numbers of complex and abstract conceptual details on network payers, protocols, addressing format and configurations (Rashid, Othman, Johan, \& Sidek, 2019). The traditional mainstream teaching method of lecturing is found to be inadequate for motivating students in network education (Zhamanov, Yoo, Sakhyeva, \& Zhaparov, 2018). The common challenge often seen in teaching computer networking and data communication is the difficulty for students to understand the complex technical concepts and to visualize the various network protocols, roles, and functions in data communication (Noor, Yayao, \& Sulaiman, 2018). More importantly, students may have further difficulty in developing the skills and ability to use higher level skills for troubleshooting and creative problem solving (Elias \& Ali, 2013).

Troubleshooting is a frequent topic and essential problem-solving skill and ability in computer network and data communication. Network troubleshooting, such as resolving issues with physical or logical connectivity, IP configuration, DNS configuration, routing, VLAN configuration, or firewall and ACLs, is a comprehensive ability to identify, understand, describe, analyze, evaluate technical problems and provide the best solutions for problem solving. Network troubleshooting often involves collaboration and communication with a team of colleagues, partners, or clients. Thus, problem-solving, teamwork, and communication are not only essential skills and competencies expected for general college education but also key learning outcomes for reputable computing programs (ABET CAC, 2018).

Team or group projects have been used in various college classes to develop students' skills in teamwork, problem solving, and communication. A team project is a type of team-based learning (TBL) that involves both collaborative learning activities among team members and individual preparation, research, and contributions. Team-based learning is an instructional method that has been shown to reduce attrition rate and improve student learning in a number of disciplines especially in science courses (Comeford, 2016). Team-based learning enables instructors to design rich learning opportunities for students to demonstrate their knowledge, skills, and abilities; it also helps to prepare students 
for deep learning and for solving complex real world problems with application of course concepts (Moore, Prewitt, Carpenter-McCullough, \& Whitworth, 2020).

However, significant research is still needed on the effectiveness of team-based learning pedagogy especially for computer network education. While TBL research shows observations on the positive change of student attitude to learning, the research field needs more empirical data on the effect of TBL on student academic performance (Artz, Jacobs, \& Boessen, 2016). Research on TBL has been inconsistent and would benefit from more contributions of primary or empirical research with thorough data reporting (Liu \& Beaujean, 2017). The study by Wang and Sbeit (2017) provides a constructive team project model for online cybersecurity education. But further studies with empirical practices and data are needed to improve computer network education and on-ground delivery as well. For example, assessment of teamwork remains a common challenge for using teamwork activities in teaching as it may lead to unfair distribution of grades among team members (Billings \& England, 2020).

This study will focus on the use of team project learning in computer network education. The goal of this research is to provide an instructional design for teaching and assessing a team project with empirical findings based on teaching experience in an undergraduate computer network and data communication course at a U.S. university. The following sections will review relevant theoretical background, provide the instructional design, describe the team project implementation and data collection method, and present the findings and discussions.

\section{BACKGROUND}

Team projects in college education are valuable learning activities for students to develop skills and competencies in team collaboration, communication, problem solving, and critical thinking and analysis that are critical to success in a professional environment. These professional skills and competencies are usually expected in the core college curriculum for a well-rounded college education. In fact, the general education curriculum criteria for the Middle States Commission on Higher Education (MSCHE) accreditation standard on the design and delivery of the student learning experience explicitly expect that students acquire and demonstrate essential skills in communication, critical analysis and reasoning, and well-reasoned judgments outside and within their academic field (MSCHE, 2015). In addition, computer networking and data communication is a common core course area for computing programs. The student outcomes for ABET accreditations for computer science, cybersecurity, information systems, and information technology programs all emphasize student abilities of complex problem analysis and resolution, solution evaluation and informed judgment, effective communication, and effective teamwork in the following program requirements (ABET CAC, 2018, p.3):

1. Analyze a complex computing problem and to apply principles of computing and other relevant disciplines to identify solutions.

2. Design, implement, and evaluate a computing-based solution to meet a given set of computing requirements in the context of the program's discipline.

3. Communicate effectively in a variety of professional contexts.

4. Recognize professional responsibilities and make informed judgments in computing practice based on legal and ethical principles.

5. Function effectively as a member or leader of a team engaged in activities appropriate to the program's discipline.

A team project for education is a form of collaborative learning that should benefit the advancement of knowledge for the team and the individual members. The social constructivist philosophy views learning as a social process of interaction in which individuals take responsibility for their own learning actions and respect the abilities and contributions of their peers or team members. Pedagogically, collaborative learning such as through a team project may lead to many benefits for teaching and learning, including positive student attitude and engaging learning environment, higher student esteem and motivation, and improved results in test scores, critical thinking, and problem solving (Artz, Jacobs, \& Boessen, 2016; Billings \& England, 2020; Laal \& Ghodsi, 2012; Lin, 2018). Prior research 


\section{Issues in Information Systems}

Volume 21, Issue 2, pp. 167-177, 2020

has identified five essential conditions for collaborative learning in a group or team setting to be successful and more productive than individual learning efforts: (1) Positive interdependence - share a common positive goal of success in learning and unite all team efforts around the common goal; (2) Promotive interaction - trust and help each other among team members to reach the group goals; (3) Individual accountability - individual member's responsibility to contribute his or her fair share to the team's success with no "free ride"; (4) Interpersonal skills - accept and support each other with effective communication and constructive conflict resolution; and (5) Group processing - reflect on member behavior and actions and seek improvements for the group (Billings \& England, 2020; Campbell \& Taylor, 2020; Johnson \& Johnson, 1994; Laal, Laal, \& Kermanshahi, 2012).

A team project is also a team-based learning (TBL) that shifts from the traditional lecture-based teaching style to more structured activities including in-class teamwork in problem solving and individual preparation outside of class (Artz, Jacobs, \& Boessen, 2016). TBL research among undergraduate students in different Economics courses has found evidence of significant positive effects of team performance on the individual test scores at all levels with little variation suggesting that "TBL is a very robust approach for helping the entire spectrum of student abilities in the classroom” (Artz, Jacobs, \& Boessen, 2016, p.410). In terms of impact on learning behavior, the study by Artz, Jacobs and Boessen observes that the TBL approach engages students, promotes exploration and discovery in learning, and builds cohesiveness of the team along with increased reports of positive learning experience and outcomes in student evaluations of the course. The team cohesiveness is important for cultivating a sense of community and interpersonal trust essential to a positive learning environment that leads to mutual acceptance of knowledge sharing (Nistor, Daxecker, Stanciu, \& Diekamp, 2015). In addition, students in a collaborative problem-based learning environment would feel less anxious and more motivated to engage in learning when they have the opportunity to receive feedback and support from their teammates (Campbell \& Taylor, 2020).

The concept of a constructive learning community should be essential to the success of team project based learning. Based on the Community of Inquiry (CoI) model, the Online Learning Community Model proposes a conceptual framework with four interacting elements for building a constructive learning community: (1) Cognitive Presence constructing meaning through sustained communication including information exchange and connecting ideas; (2) Social Presence - projecting personal characteristics into community with open communication seeking group cohesion and encouraging collaboration; (3) Teaching Presence - designing educational experience and providing facilitation and instructions; and (4) Assessment Presence - ongoing process of evaluating and improving student learning with constructive feedback guided by measurable performance expectations, criteria, and quality standards (Wang, 2015; Wang \& Sbeit, 2017). The elements in the Online Learning Community Model also apply to on-ground team project based learning, which should include the important role of assessment to evaluate and motivate students' learning while incorporating social presence and cognitive presence for the success of both team and individuals in learning. Without fair assessment in team-based learning, high achievers may be more likely to abandon teamwork and pursue individual-oriented effort if they perceive less effort from teammates (Lee, Kim, \& Byun, 2017). "One of the most common complaints about group work is that it can lead to an unfair distribution of grades with weaker team members being rewarded for the work of stronger members” (Billings \& England, 2020, p.3).

Peer evaluations should be an important activity for team-based learning and assessment of team members. Peer evaluations are used one of the factors in grading teamwork because team members tend to have more and direct knowledge of teammates' contributions than instructors and peer evaluations can motivate conducive individual member behavior for team success (Liu \& Beaujean, 2017). Awareness of team activities and peer evaluations and assessment used in a team project based learning environment could help to reduce the free-rider effect and sustain team member participations (Lin, 2018). Peer evaluations also help to develop a strong sense of responsibility as part of the college education. Peer reviews and assessment help to ensure individual accountability to the team by documenting and assessing each member's contributions to the team (Campbell \& Taylor, 2020). Additional research has reached similar findings that peer evaluations are an important component of team-based learning that enables college students to take responsibility for their own learning and for other learners on the team as well (Moore, Prewitt, Carpenter-McCullough, \& Whitworth, 2020).

Collaboration and individual reflections are not mutually exclusive, and individual reflections could be a valuable component of team-based learning. Reflective learning may be helpful to the development of high levels of learning 


\section{Issues in Information Systems}

Volume 21, Issue 2, pp. 167-177, 2020

and competencies such as analyzing, evaluating, and creative problem-solving. Gibbs (1988) applies individual reflections to the learning process and develops and formulates a reflective cycle of learning that consists of six key components: (1) Description - Recall and describe what happened in the learning activity or experience; (2) Feelings - Identify learner's feelings and reactions to the experience; (3) Evaluation - Make value judgements about the pros and cons of the experience; (4) Analysis - Bring outside experience and research findings to help understand the situation; (5) Conclusions - Draw conclusions on what has been learned from the experience and analysis; and (6) Personal Action Plans - Decide and make plans on what steps to take next time based on what has been learned. The components of Evaluation, Analysis, Conclusions and Personal Action Plans are important outcomes for general education and computing programs, which are also high-level skills and competencies defined in the revised Bloom's Taxonomy of learning (Anderson \& Krathwohl, 2001). In addition, individual self-assessment and reflections help students to reach a better understanding of the assessment and grading of teamwork (Billings \& England, 2020).

\section{INSTRUCTIONAL DESIGN}

This section presents the proposed instructional design of a team project for teaching network troubleshooting in an undergraduate network and data communication course. The instructional design includes the pedagogical objectives, components, steps, and relationships in the team project process. The pyramid and steps in Figure 1 below show the team project design model proposed for this study. 


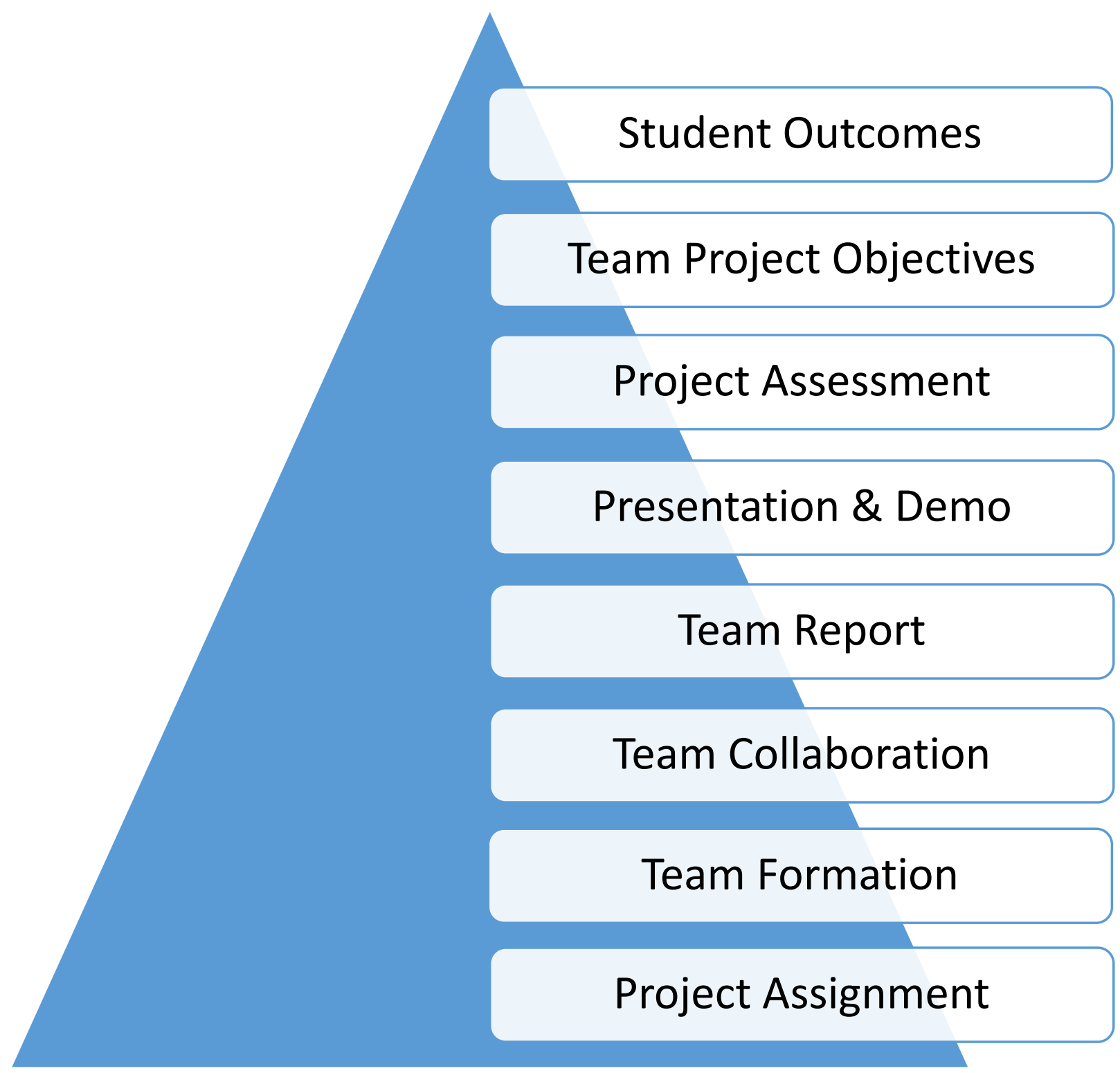

Figure 1. Team Project Design Model

The initial step at the bottom of the pyramid in Figure 1 begins with the project assignment which must be done with heavy teaching presence and planning. The project assignment should be formulated and given to the students at the beginning of the project. The assignment should include clear learning objectives to be accomplished through the project. Pedagogically, the learning objectives should support the student outcomes for the program and the course. The project assignment should also include clear instructions, expectations, guidance, deliverables, due date, methods of evaluation and assessment, grading rubric, and the weight of the project scores in the student course grade. Clear project assignment instructions given at the beginning are a critical first step for student success in the project.

Step 2 in the team project design model is team formation. There are various ways of forming groups for a team project with numerous factors to consider. A simple solution is using a random selection or pseudo-random selection with a hashing algorithm based on a numerical or alphabetical order of student last names for group membership (Roberts \& McInnerney, 2007; Wang \& Sbeit, 2017). This solution is not only easy to implement but objective, fair, and 


\section{Issues in Information Systems}

Volume 21, Issue 2, pp. 167-177, 2020

transparent to all students in the class. The method also presents a more realistic learning opportunity for students close to the real world where employees are often assigned to teams and tasks and may not have the privilege to decide who to work with for a collaborative project.

Step 3 in the team project design is team collaboration, which includes all team and individual efforts and activities both in the class and outside of the class till the completion of the project. The team collaboration activities may include individual research and preparations outside of the class and collaborative problem-solving exercises in a class (Artz, Jacobs, \& Boessen, 2016). The teamwork activities should also include team discussions, peer reviews and feedback, lab work, and research work. Team discussions should be productive interactions for the team members to share their thoughts, ideas, plans, research findings, progress updates, and suggestions for teammates to help each other. The team collaboration should maintain a constructive learning community with the instructor's teaching presence and guidance (Wang \& Sbeit, 2017).

Step 4 in the team project design process is the delivery of team report. The team report should be the culmination of the teamwork on the given project assignment and meet the requirements and expectations laid out in the project assignment. The team report should have gone through brainstorming, outlining, multiple drafts, and revisions supported by team discussions, research findings and hands-on test results. The team report should reflect contributions of all team members instead of one person on the team who does all the work. The final version of the team project report for submission should follow the professional format required or recommended and should be checked for plagiarism for academic integrity.

Step 5 of the team project design is the team presentation and demo, where each team present their project along with a hands-on demonstration of their lab work or data and findings to the class. This is for students to share their different troubleshooting problems, solutions, and research findings to maximize their learning, which is especially important for troubleshooting and problem-solving in computer networking courses. The presentation is also a valuable opportunity for students to practice their professional communication skills.

Step 6 in the team project design process is the project assessment to measure the effectiveness of the teamwork relative to the learning objectives. The assessment should of course include instructor grading of the team deliverables of the team report and presentation and demo based on the transparent grading rubric distributed for these deliverables. The assessment should also include student self-assessment, reflections, and peer evaluations from the student perspectives which provide additional information on the team members' roles, responsibilities, and contributions (Campbell \& Taylor, 2020; Liu \& Beaujean, 2017; Moore, Prewitt, Carpenter-McCullough, \& Whitworth, 2020).

Step 7 in the team project design is to consider and review the learning objectives for the project. The instructor should review and see if the specific learning objectives are mapped to and support the student outcomes for the program and the course. The instructor should also review the designed activities and deliverables of the project to see if they are mapped to and support each learning objective of the project.

Finally, step 8 of the team project design process is to review the student outcomes for the program and see if any and what outcomes are supported by the learning objectives of the project with assessment data. The student outcomes are the peak of the pyramid in the team project design, which reflect the most important end product of the learning process through a team project. During the team project design process, the instructor may alternatively reverse the order of the steps starting with the student outcomes step and reach the project assignment in the end.

\section{IMPLMENTATION \& DATA COLLECTION}

Based on the Team Project Design Model presented above, a team project for network troubleshooting was implemented among selected undergraduate computer networks and data communication classes at a university in the northeast of the United States for three semesters from spring 2019 to spring 2020. This section presents the instructional experience of the project implementations and the methodology for data collection.

The task of the Team Project was for each team to identify a networking problem affecting network service availability, reliability or security and conduct research and hands-on testing to propose the best solution to the problem. The team 


\section{Issues in Information Systems \\ Volume 21, Issue 2, pp. 167-177, 2020}

project assignment with detailed written instructions was given to each class at the beginning of the 15-week semester. The project instructions include learning objectives, deliverables, expectations and guidance on each of the deliverables, due date, methods of grading and assessment, grading rubric, and the weight of the project scores in the student course grade (100 points and $10 \%$ of course grade). The project deliverables included a project report, a presentation and hands-on demo, and a self and peer evaluation. The deliverables were due the week before the final exam, allowing students 14 weeks to work on the project.

Team memberships were announced in class and posted in Blackboard in the second week after student introductions to each other during the first week. A simple pseudo-random selection with a hashing algorithm based on a numerical and alphabetical order of student last names was used for team formation and membership with 4 or 5 students assigned to each team. This is an objective and fair team formation based on prior research (Roberts \& McInnerney, 2007; Wang \& Sbeit, 2017), and rare adjustments were made for students with documented needs for accommodations.

There were extensive learning activities and team collaboration for the team project with teaching presence and guidance from the instructor. A weekly in-class team meeting for discussions for 15-30 minutes was required for each team. The in-class meeting and discussions were for the team to provide weekly updates and share their thoughts, plans, preparations, research findings, software tools and data for lab work, and suggestions for the next step. At the end of each team meeting, the instructor had each team take turns to brief the class on their discussions, project progress, and any questions or difficulties encountered and to be addressed by the instructor. Before or after each class, the teams were encouraged to meet physically or virtually via Google Hangout/Meet for additional collaborations and post their contributions and discussions in Blackboard Group Discussions area.

Each team member was required to submit 3 file deliverables in his or her account in Blackboard: The final team report paper, the PowerPoint presentation slides, and the self and peer evaluation form. The team report paper should meet the length requirements and minimum number of research sources given in the project assignment. The report should also use either APA or IEEE editorial format for references and source citations, and both APA and IEEE format manuals were provided to the class. The team report paper submissions were screened for plagiarism using SafeAssign embedded in the Blackboard assignment.

All teams for the project in spring 2019 and fall 2019 presented their project with hands-on demos to the class when the project was due. All team members participated in the presentation and demo to share their problems, solutions, data from lab work and research. For the spring 2020 semester, as an adjustment for the Covid-19 pandemic around mid-March or shortly after midterm, all on-ground classes were converted to online using Blackboard with asynchronous participations from students due to work and travel schedules of some students. As a result, the teams submitted their deliverables with electronic presentations including lab work and data in place of the physical presentations. The teams were asked to share their presentations with the class in Blackboard discussions.

The team deliverables were assessed and graded using the grading rubric posted since the beginning of the project. The rubric reflects key expectations such as network problem description, quality of the troubleshooting solution, presentation and hands-on demo, and writing as communication, each graded at different levels - Outstanding (95\%$100 \%)$, Excellent (90\%-94\%), Satisfactory (80\%-89\%), or Below Expectations ( $<80 \%)$ with specified number of point range for each level. However, individual grade may vary with individual record of attendance, participation, contributions, and peer reviews and observations from teammates as collected from the confidential self and peer evaluation form. Figure 2 below captures the Self \& Peer Evaluation form with definitions of the evaluation criteria attendance, contribution, collegiality, and communication.

The specific learning objectives for the team project are "to enhance and demonstrate student knowledge and skills on diagnostics of network issues, troubleshooting, and skills in critical thinking, problem solving, communication, and technical research and presentation.” The learning activities and assessment criteria all support the objectives of the project. The team project objectives contribute to the competencies of communication, critical thinking and analysis, and well-reasoned judgment expected in the general education curriculum for college education (MSCHE, 2015). The team project objectives are also mapped to and support the student outcomes of problem analysis and resolution, solution evaluation and informed judgment, effective communication, and effective teamwork expected for computing program accreditation by ABET (ABET CAC, 2018). 


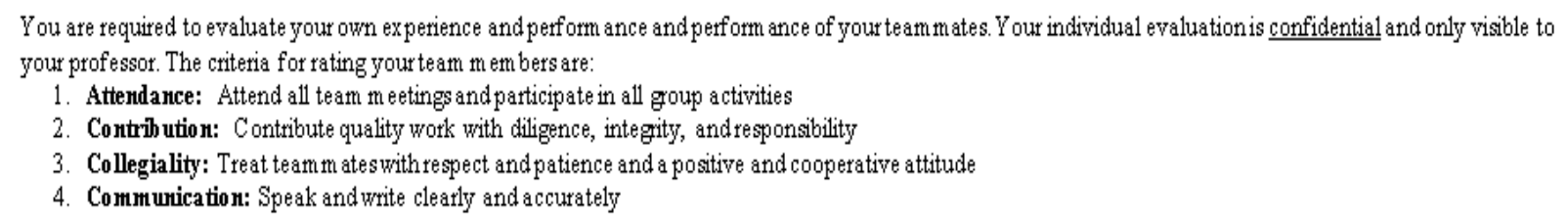

Rate yourself and each team mate using the criteria above and the rating scale from 1 to 10 below. Give additional com ments on each mem ber in the final column. 1-2 Very Poor; 3-4 Poor; 5-6 Average; 7-8 Good; 9-10 Excellent

\begin{tabular}{|c|c|c|c|c|c|}
\hline Add Names Below & $\begin{array}{c}\text { Attendance } \\
(1-10)\end{array}$ & $\begin{array}{c}\text { Contribution } \\
(1-10)\end{array}$ & $\begin{array}{c}\text { Collegiality } \\
\text { (1-10) }\end{array}$ & $\begin{array}{c}\text { Commutication } \\
\text { (1-10) }\end{array}$ & Additional Comments to Explain/Support Your Ratings \\
\hline \multicolumn{6}{|l|}{ Yourself: } \\
\hline \multicolumn{6}{|l|}{ Teammate 1: } \\
\hline \multicolumn{6}{|l|}{ Teammate 2: } \\
\hline \multicolumn{6}{|l|}{ Teammate 3: } \\
\hline Teammate 4: & & & & & \\
\hline
\end{tabular}

Also rate your own experience with the Team Learning Community in the following two questions in a scale from l (lowest) to 10 (highest):

1. What is your com fortlevel in interacting and working with your team com m urity?

2. What level of individual accomplishm ent have you reached in this team environm ent?

Figure 2. Self and Peer Evaluation Form

The aggregate data on the team and individual performance and success rates on the team project were collected along with student self and peer evaluations of the team members and relevant course evaluation data. These aggregate data items are indicators of the accomplishments of the project objectives and learning outcomes as well as the effectiveness of the course learning community and environment (Wang \& Sbeit, 2017). Student peer evaluations and standard course evaluations are first-hand qualitative assessments of the team project design and the learning community based on their direct learning experience. The collected data were processed with Microsoft Excel. The next section will present the findings and discussions on the team project participation, student performance, student peer evaluations, and relevant course evaluations.

\section{FINDINGS \& DISCUSSIONS}

\section{Team and Individual Assessment Results}

The assessment results of the team and individual success rates on team project are direct indicators of student performance, learning outcomes and the effectiveness of the team project approach. Table 1 below presents the summaries of the team and individual success rates on the team project. The average team grade, average individual grade, team success rate, and individual success rate for each of the three semesters for the study are displayed. The $N$ column is the total number of students selected for each semester. The $N$-T column is the number of teams, and the team size is either 5 members or 4 members based on a hashing algorithm. The Average-T column shows the average team grade on the team project for each semester in percentage scale. The Average-I column shows the average individual grade on the team project in percentage scale. The Success-T and Success-I columns indicate the rate of 


\section{Issues in Information Systems}

Volume 21, Issue 2, pp. 167-177, 2020

success for each of the teams and individuals respectively by semester. The team grade is assessed using the team project rubric, and the individual grade is based on the team grade, record of individual participation and contribution, and peer review results. The expected score (in percentage scale) for success is $80 \%$ or higher. The Pearson correlation coefficient value $\boldsymbol{r}$ between Average-T and Average-I is 0.79. The $\boldsymbol{r}$ value indicates a positive bivariate correlation between the average team performance and the average individual performance on the team project. In addition, the high percentages of team success and individual success in the team project reflect the effectiveness of the team project instructional design.

Table 1. Summary of Team and Individual Assessment Results

\begin{tabular}{|l|c|c|c|c|c|c|}
\hline \multicolumn{1}{|c|}{ Semester } & $\boldsymbol{N}$ & $\boldsymbol{N}$-T & Average-T & Average-I & Success-T & Success-I \\
\hline Spring 2019 & 14 & 3 & $91.24 \%$ & $90.31 \%$ & $100 \%$ & $92.86 \%$ \\
\hline Fall 2019 & 29 & 6 & $92.17 \%$ & $92.54 \%$ & $100 \%$ & $96.55 \%$ \\
\hline Spring 2020 & 25 & 5 & $91.36 \%$ & $91.93 \%$ & $100 \%$ & $96 \%$ \\
\hline
\end{tabular}

\section{Student Peer Review Results}

Table 2 below presents the aggregate results on student peer reviews for the three semesters based on 1-10 scale.

Table 2. Summary of Student Peer Review Results

\begin{tabular}{|l|c|c|c|c|}
\hline \multicolumn{1}{|c|}{ Semester } & $\boldsymbol{N}$ & $\boldsymbol{N}$-T & $\begin{array}{c}\text { Average } \\
\text { Reviews }\end{array}$ & Average-I \\
\hline Spring 2019 & 14 & 3 & 9.17 & $90.31 \%$ \\
\hline Fall 2019 & 29 & 6 & 9.48 & $92.54 \%$ \\
\hline Spring 2020 & 25 & 5 & 9.26 & $91.93 \%$ \\
\hline
\end{tabular}

Average Reviews shows the average of peer review scores each student received from his or her teammates on participation, contribution, collegiality, and communication. The average value indicates a comprehensive perception from one's peers in the group. The Average-I is the average individual grade achievement on the team project in each class, which is used for the privacy of individual student grade. The Pearson correlation coefficient $\boldsymbol{r}$ value between the average peer review results for each student and the average individual grade on the team project is 0.88 . The $\boldsymbol{r}$ is statistically significant and indicates a fairly strong correlation on average between a student's actual performance and peer perceptions on the student's performance. The correlation suggests that student peer evaluations can be used as one of the factors in student performance assessment.

\section{Student Perceptions on Team Project \& Feedback}

Table 3 below is an aggregate data summary of student evaluations related to the team project in the course survey.

Table 3. Summary of Student Evaluations of Team Project and Learning Community

\begin{tabular}{|l|c|c|c|c|}
\hline \multicolumn{1}{|c|}{ Semester } & $\boldsymbol{N}$ & $\begin{array}{c}\text { Grading \& } \\
\text { Feedback }\end{array}$ & $\begin{array}{c}\text { Project \& } \\
\text { Course Content }\end{array}$ & $\begin{array}{c}\text { Project } \\
\text { Value }\end{array}$ \\
\hline Spring 2019 & 14 & 4.86 & 4.79 & 4.93 \\
\hline Fall 2019 & 29 & 4.88 & 4.89 & 4.76 \\
\hline Spring 2020 & - & - & - & - \\
\hline
\end{tabular}

Column $N$ is the number of anonymous participants for each semester. The three categories of student perceptions are: (1) Grading \& Feedback - The instructor's grading and feedback was clear, consistent, and timely; (2) Project \& Course Content - The projects or assignments reflected the course content; and (3) Project Value - The projects or 


\section{Issues in Information Systems}

Volume 21, Issue 2, pp. 167-177, 2020

assignments helped students to learn the course material. The score range for each category is from 0 (MIN) to 5 (MAX). The results show very positive student perceptions and high ratings in all three categories, which indicate high value of the team project and instructor feedback. In addition, students' satisfaction with the assessment presence (clear, consistent, and timely grading and feedback) indicates a constructive and effective learning community (Wang, 2015). The spring 2020 evaluation results are not available yet when this paper is submitted. The course evaluation instrument is the university-wide standard practice used for many years with consistent validity and reliability.

\section{CONCLUSIONS}

The highly technical and complex subject matter in computer networking and data communication makes it one of the most challenging areas for teaching and learning. Problem solving, such as troubleshooting computer networks, is a frequent and significant professional task that involves skills and competencies in team collaboration, critical thinking and analysis, creative problem solving, and effective communication. This research proposes a team project pedagogical approach with instructional design for teaching network troubleshooting and related skills. This study shares the experience of implementing and assessing a team project used for an undergraduate networking course and contributes the empirical data from three semesters. The assessment results indicate a positive correlation between the average team performance and average individual performance on the project, suggesting that there is no conflict of interest between team and individual accomplishments. The peer evaluation from teammates was found to be positively related to the actual average individual performance on the team project. In addition, student evaluations of the project assessment and feedback and the value of the project indicate effectiveness of the team project and a positive learning community associated with the project and the course.

This study contributes valuable empirical data on a significant pedagogical research area. However, the sample size for this study was quite limited. Future studies may expand to a larger sample of student participants. This study is a preliminary effort on the use of team project in an on-ground technology course environment. Future research may compare the practices and outcomes of using the team project approach between on-ground and online learning environment. In addition, computer networking and data communication is a broad and complex field with many subdomains and emerging technologies. Future research may focus on the team project approach in a specific or emerging domain such as software defined networking (SDN).

\section{REFERENCES}

ABET CAC (Computing Accreditation Commission). (2018). Criteria for Accrediting Computing Programs (20192020). Retrieved from https://www.abet.org/

Anderson, L.W., \& Krathwohl, D.R. (2001). A taxonomy for learning, teaching, and assessing, Abridged Edition. Boston: MA: Allyn and Bacon.

Artz, G.M., Jacobs, K.L., \& Boessen, C.R. (2016). The whole is greater than the sum: An empirical analysis of the effect of team based learning on student achievement. NACTA Journal, 60(4), 405-411.

Billings, S., \& England, M. (2020). First year Computer Science projects at Coventry University: Activity-led integrative team projects with continuous assessment. CEP 2020, January 9, 2020, Durham, UK. 1-4.

Campbell, C.G., \& Taylor, T.Z. (2020). Assessing student learning and knowledge transfer using principles of teambased learning and bridge assignments in large introductory statistics classes. Scholarship of Teaching and Learning in Psychology, 2020, 6(1), 15-23.

Comeford, L. (2016). Team-based learning reduces attrition in a first-semester general Chemistry course. Journal of College Science Teaching, 46(2), 43-46. 
Elias, M.S., \& Ali, A.Z.M. (2013). Survey on the challenges faced by the lecturers in using Packet Tracer simulation in computer networking course. Procedia - Social and Behavioral Sciences, 131(2014), 11-15.

Gibbs, G. (1988). Learning by doing: A guide to teaching and learning methods. Oxford, UK: Oxford Polytechnic.

Johnson, R. T. and Johnson, D. W. (1994). An overview of cooperative learning. In Thousand, J., Villa, A. \& Nevin, A. (Eds.), Creativity and collaborative learning (pp.2-21). Baltimore, MD, USA: Brookes Publishing.

Laal, M., \& Ghodsi, S. M. (2012). Benefits of collaborative learning. Procedia - Social and Behavioral Sciences, 31(2012), $486-490$.

Laal, M., Laal, M., \& Kermanshahi, Z. K. (2012). 21st century learning: Learning in collaboration. Procedia Social and Behavioral Sciences, 47(2012), 1696-1701.

Lee, H., Kim, H., \& Byun, H. (2017). Are high achievers successful in collaborative learning? An explorative study of college students' learning approaches in team project-based learning. Innovations in Education and Teaching International, 54(5), 418-427.

Lin, J. (2018). Effects of an online team project-based learning environment with group awareness and peer evaluation on socially shared regulation of learning and self-regulated learning. Behavior \& Information Technology, 37(5), 445-461.

Liu, S.C., \& Beaujean, A.A. (2017). The effectiveness of team-based learning on academic outcomes: A metaanalysis. Scholarship of Teaching and Learning in Psychology, 2017, 3(1), 1-14.

Moore, V.J., Prewitt, E.M., Carpenter-McCullough, A.J., \& Whitworth, B.A. (2020). Teamwork makes the dream work:Using team-based learning in the science classroom. Journal of College Science Teaching, 49(3), 43-46.

MSCHE (Middle States Commission on Higher Education). (2015). Standards for Accreditation and Requirements of Affiliation, 13th ed. Retrieved from www.msche.org

Nistor, N., Daxecker, I., Stanciu, D., \& Diekamp, O. (2015). Sense of community in academic communities of practice: Predictors and effects. High Education, (2015), 69:257-273. DOI 10.1007/s10734-014-9773-6.

Noor, N.M.M., Yayao, N., \& Sulaiman, S. (2018). Effectiveness of using Cisco Packet Tracer as a learning tool: A case study of routing protocol. International Journal of Information and Education Technology, 8(1), 11-16.

Rashid, N.A., Othman, Z., Johan, R., \& Sidek,S. F. H. (2019). Cisco Packet Tracer simulation as effective pedagogy in computer networking course. International Journal of Interactive Mobile Technologies (iJIM), 13(10), 418. https://doi.org/10.3991/ijim.v13i10.11283

Roberts, T. S., \& McInnerney, J. M. (2007). Seven problems of online group learning (and their solutions). Educational Technology \& Society, 10(4), 257-268.

Wang, P. (2015, August). Assessment of asynchronous online discussions for a constructive online learning community. International Journal of Information and Education Technology, 5(8), 598-604.

Wang, P., \& Sbeit, R. (2017). A constructive team project model for online cybersecurity education. Issues in Information Systems, 18(3), 19-28.

Zhamanov, A., Yoo, S., Sakhyeva, Z., \& Zhaparov, M. (2018). Implementation and evaluation of flipped classroom as IoT element into learning process of computer network education. International Journal of Information and Communication Technology Education, 14(2), 30-47. 